\title{
ПРЕВЕНЦИЯ СУИЦИДА, НОВЫЕ ГОРИЗОНТЫ
}

\author{
Борохов А. (Многопрофильный госпиталь "Герцог", Иерусалимский \\ Университет, Иерусалим, Израиль) \\ Борохов Б. (Реабилитачионно-корригирующая программа "СЭЛА" для детей \\ с проблемами поведения, Иерусалим, Израиль) \\ adsamuray@gmail.com,borisdo69@gmail.com

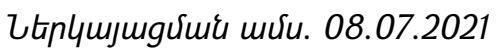

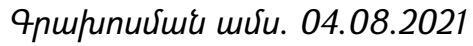

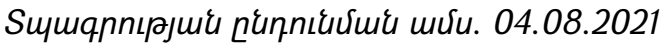

В статье представлена концептуальная модель оценки суицидальной активности и риска. Эта модель составлена с учетом расширенной и дополненной биопсихосоциальной модели Георга Энгеля (Engel G., 1977), которая состоит из трех типов конструктов: биологического, психологического и социального. Собственно конституциональный психотип человека это генетическая предрасположенность каждого конкретного человека, принадлежащего к одному из трех соматотипов (нормостенический, астенический, гиперстенический), и ожидаемая базовая индивидуальная поведенческая реакция (Борьба-Бегство-Заморозка). Последняя почти всегда проявляется как реакция на стрессовую ситуацию. В клинической психологии принято считать, что почти любой человек, который действительно охвачен суицидальными мыслями, не только не имеет, но и не ищет альтернативного решения. Образно говоря, он развивает "туннельное зрение», то есть видит минимальный набор решений своей проблемы, точнее одно - фатальное. Таким образом, мы пришли к выводу, что необходимо создать систему «внешних и внутренних якорей», удерживающих пациента от совершения суицидального акта. Таким образом, мы пришли к выводу, что необходимо создать систему «внешних и внутренних якорей», удерживающих пациента от совершения суицидального акта. В его основе лежало несколько базовых вопросовконструктов, ответы на которые можно было получить в процессе диалога врач / психолог-пациент. Таким образом, была построена индивидуальная схема психотерапевтического лечения, цель которой - удержать человека от суицидальной попытки. Четыре основных вопроса:“"Что? ", «Кто? », «Что?» и как?". В статье также представлена специально разработанная авторская шкала (А.В.)*, которая получила название «суицидальной линейки», BARS-2000 (Rapid Active Calculation of Suicidality), которая успешно применялась не только в приемных покоях психиатрических больниц для гражданского населения, а также для проверки лиц, унтерофицеров призывной службы Сил обороны Израиля. 
Ключевые слова: суицид, психотип, психофакторы, шкала самодиагностики, превенция.

DOI: https://doi.org/10.46991/SBMP/2021.4.2.105

Самоубийство, всегда было одной из сложнейших проблем человеческой психики и как сложная мозаика, несёт в себе массу общемедицинских, психиатрических, психологических, фрилософских, религиозных, этическонравственных и этно-культурологических компонентов. Каждому человеку отпущен его индивидуальный жизненный срок, и несмотря на существование естественного природного предохранителя - инстинкта самосохранения, его добровольный выбор ухода из жизни, является совокупностью внешних причин и внутренних мотивов $[2,4]$. Инстинкт самосохранения является ведущим из трех основных инстинктов человека, так как это врожденная фрорма поведения, направлена на защиту собственной жизни и здоровья. При его нарушении или отсутствии, два остальных (голода и сексуальный) просто теряют свой смысл. Что же заставляет человека рассматривать собственную смерть, как единственное и окончательное решение реальной или мнимой проблемы [4]? Мы попытались понять, почему одни и те же события, для одних людей являются фатальными и приводят к попытке самоубийства и напротив, для других хотя, и также являются стрессовым фактором, но не рассматриваются личностью как несовместимые с жизнью $[1,4]$.

Нами была разработана собственная концептуальная модель с учетом расширенной и дополненной био-психо-социальной модели Георга Энджела, которая состоит из трёх видов конструктов: биологических (генетических, анатомо-фризиологических, нейрохимических, гуморальных и т.д.), психологических (отражающих ментальные процессы головного мозга, эмоциональноволевую сореру и поведенческие реакции), социальных (факторы макро и микросоциума, социально-экономические, религиозные и этно-культуральные факторы) $[3,5,6,7]$.

Собственно, конституциональный психотип человека - это генетическая предрасположенность каждого конкретного человека, относящегося к одному из трех соматотипов (нормостеник, астеник, гиперстеник) и ожидаемой базовой индивидуальной поведенческой реакции (Fight _Flight -Freeze), которая практически всегда проявляется в рамках ответа на стрессовую ситуацию. Чем сильнее фрустрирующая ситуация, тем более явно проявляется каждая из реакций, характерных для собственного психотипа. С позиции био-психо социальной модели личности, универсальным индикатором уровня кризисной ситуации, является уровень утраты волевого контроля над своей приоритетной поведенческой реакцией (Fight-Flight-Freeze). Более того, такие фракторы как физическое и\или психическое истощение индивидуума, а также 
невозможность активно использовать привычные ультимативные защитные механизмы, реально могут привести к попытке самоубийства. При отсутствии диагностирования психопатологии, самоубийство - может рассматриваться как осознанный, добровольный выбор собственной смерти, в качестве оптимальной, кардинальной коррекции индивидуальной психотравмирующей ситуации. Таким образом, человек видит в своей смерти, альтернативу существованию, заполненному исключительно страданиями, в которых нет никакого смысла. Личность, в своем поведении руководствуется не только фундаментальной - врождённой тактикой поведения, которая является наиболее оптимальной по затратам фризических и интеллектуальноэмоциональных ресурсов, но и тактиками, которые были им приобретены в результате воспитания и самовоспитания (на основании собственного личного жизненного опыта).

Астенический психотип (шизоиды, эктоморфы), это те люди, у которых угол схождения скелетных реберных дуг составляет меньше, чем 90 градусов. Чем он меньше, тем сильнее выражены личностные особенности собирательный образ - «Цветок», от Flos (лат.) - цветок, краса, лучшая часть. А также от контекста Floreo (лат.)-цвести, блистать, сиять, отличаться, находиться на вершине славы. Люди с фрундаментальной тактикой поведения («беги»). Это те, чья доминирующая тактика решения проблем, является фризическим, интеллектуальным или психологическим бегством ("во внутрь себя"). Люди, для которых приоритетной поведенческой реакцией в критической ситуации является Flight («беги»)

Гиперстенический психотип (эндоморфы, пикники) это те люди, у которых угол схождения скелетных реберных дуг составляет больше чем 90 градусов. Чем он больше, тем сильнее выражены личностные особенности собирательный образ - «Горшок», от Olla (лат.) - горшок, в контексте латинской пословицы «lpsa olera olla legit» - "Горшок сам себе выбирает овощи", т.е. каждый человек живет, следуя своим склонностям. Люди, чья приоритетная линия поведения для решения проблемы заключается в терпении, выжидании, длительном и детальном планировании, то есть те, для которых приоритетной поведенческой реакцией в критической ситуации является Freeze («замри»).

Нормостенический психотип (атлетики, мезоморфы) это те люди, у которых угол схождения скелетных реберных дуг составляет практически 90 градусов. Отклонение более, чем на пять градусов меньше, дает проявление личностным особенностям, характерным для двух других типов, но в менее выраженной форме. Собирательный образ - «Садовник», от Hortulanus (лат.) "Садовник». Мы исходили из латинского выражения Homo Agens - Человек Деятельный, т.е. психотип, занимающий конкретную активную позицию по отношению к окружающему миру. Люди с фрундаментальной тактикой 
поведения - («сражайся») это те, чья приоритетная тактика решений проблемы - физическое и психическое сопротивление, несмотря ни на что. Люди, для которых приоритетной поведенческой реакцией в критической ситуации является Fight («сражайся»).

Как мы все знаем, практически любой индивидуум, по-настоящему охваченный суицидальными мыслями, ни только не имеет, но и не ищет альтернативного решения. Образно говоря, у него, образуется" туннельное зрение", то есть он видеть очень минимальный диапазон решений своей проблемы, точнее одно - фратальное.

Поэтому, мы пришли к выводу о необходимости создания системы "внешних и внутренних якорей", удерживающих пациента от совершения суицидального акта. В её основу легли несколько базовых вопросовконструктов, ответы на которые можно было бы получить в процессе диалога врач\психолог-пациент. Таким образом, и выстраивалась индивидуальная схема психотерапевтического лечения, целью которой, является удержание человека от суицидальной попытки. Итак, четыре базовых вопроса:

"Что?"- какие именно ценностные ориентации в жизни являются личностно-ориентированными и помогают ему справляться с трудными жизненными ситуациями. Например, интересная работа, ответственность, религия, стыд перед окружающими, забота о близких и т.д. "Кто?" - какие именно "значимые другие" помогают ему справляться с этими трудными жизненными ситуациями. Например, друзья, родственники, дети, забота о домашних питомцах и т.д. "Чем?" - посредством чего можно вернуть утраченный интерес к жизни. Например, создание новой цели. Эта новая цель, должна быть построена как многоступенчатая пирамида, состоящая из небольших целей, подъём по ступеням которой должен быть постепенным и реально осуществимым для пациента. "Каким образом?" - изменение или дополнение чего в жизни может вернуть и \или улучшить удовлетворенность жизнью. Например, полная занятость в течение дня, овладение новыми навыками, занятие собственным хобби, мониторинг успехов и настроения, ффизическая нагрузка и т.д.

Каждый из этих психотипов сталкивается или может столкнуться с теми фррустриструющими ситуациями, которые ломают не только привычные стереотипы поведения, но и механизмы защиты, приводя индивидуума к мыслям и \или действиям, связанным с добровольным уходом из жизни. Исходя из этого, приходим к следующему выводу: доминирующими причинами для каждого из типов будут различные угрожающие фракторы. Для цветков -это страх, для горшков- это стыд, для садовников- нарушение привычной активности. Подвергаясь сильной стрессовой реакции или же многократно повторяющейся фррустрирующей ситуации, каждый психотип реагирует 
согласно доминирующем способе реагирования. Астеник-бегство, Гиперстеникзамирание, Нормостеник- активное сопротивление. Постепенно механизмы истощаются, так и не приводя к желаемому результату. Таким образом, по нашим наблюдениям происходит "сбой программы", когда астеник- "не может убежать", гиперстеник- "не может спрятаться", а нормостеник - "не может больше сражаться". На фоне этого истощения ресурсов и отсутствия других адаптивных стратегий может развиться депрессия, а за тем и появляются суицидальные мысли.

Травмирующими факторами, мы называем те фракторы, которые нарушают адекватность поведения, вследствие искаженного восприятия самовосприятия. Согласно вышесказанному, все травмирующие факторы можно разделить на три группы:

- Биофакторы - это те факторы, которые приводят к суицидальному поведению, из-за нарушения самовосприятия, как целостного, здорового нормально функционирующего биологического организма. Через воздействие этих факторов, происходит искаженное восприятие, создавшейся стрессогенной ситуации, в которой сам человек воспринимает себя - «человеком, испытывающим невыносимые физические и душевные муки из-за тяжелого увечья, хронической болезни или, например, длительной боли».

- Социофакторы - это те фракторы, которые приводят к суицидальному поведению, из-за нарушения самовосприятия, когда полноценной социализированной и интегрированной единицы общества, чей имеющейся собственный статус искажён или утерян. Через воздействие этих факторов, происходит искаженное восприятие, создавшейся стрессогенной ситуации, в которой индивид воспринимает себя «униженным и оскорбленным человеком и из-за нарушения социального статуса, испытывающим невыносимые физические и душевные муки».

- Психофакторы - это те фракторы, которые приводят к суицидальному поведению, из-за нарушения самовосприятия, в качестве психически полноценной и скомпенсированной личности. Через воздействие этих факторов, происходит искаженное восприятие, создавшейся в условиях стрессогенной ситуации, в которой личность воспринимает себя «испытывающей, из-за утраты своей собственной психической целостности и индивидуальности, невыносимые физические и душевные страдания ".

Существует достаточно большое количество тестов и шкал для оценки суицидальной активности и риска. Но на практике эти методики достаточно громоздки и не соответствуют реальным требования быстрой оценки и принятия решения при ургентных состояниях или экстренной ситуации. 
Поэтому и была специально разработана авторская шкала (А.Б)* , которая называется "суицидальная линейка", БАРС-2000 (Быстрый Активный Расчёт Суицидальности), которая успешно применялась не только в приёмных покоях психиатрических больниц для гражданского населения, но и для проверки лиц, солдатско-сержантского состава срочной службы армии Обороны Израиля, обратившихся за психолого-психиатрической помощью (2005-2007).

Этот метод хорош не только своей простой, но и тем, что осуществляется двойной контроль как со стороны самого пациента (субъективный), так и со стороны психотерапевта (объективный).

Рисуется линия, на неё наносятся метки, от 0 до 10. Где 0 - это минимум, то есть отсутствие каких-либо суицидальных тенденций, а 10- максимум, непреодолимое желание свести счёты со своей жизнью. Пациенту перелагается лично пометить над линией точку, над соответствующей цифрой, соответствующей силе его суицидального желания.

Итак: 0 - это отсутствие каких - либо суицидальных мыслей и тенденций. В идеале, в процессе лечения фрармакологического и\или сочетанного фармакологического и психотерапевтического, мы стремимся снизить суицидальную активность до 0-1

1-2 - суицидальные мысли присутствуют, но они транзиторны и единичны. Они могут возникать как ответная реакция на острую стрессовую ситуацию, индивидуально- значимую для пациента. Однако, сам пациент относится к ним критически, а также способен подавлять и контролировать их. Важно отметить, что сам пациент ищет и получает поддержку со стороны окружающих его людей.

3-4 - суицидальные мысли начинают кристаллизоваться, они более постоянны, занимают значительную часть времени бодрствования и могут фрагментарно присутствовать в сновидениях. Происходит первичный отбор способа суицида. Теперь эти мысли возникают уже и без связи со стрессовой ситуацией. Пациент сомневается в возможности получить настоящую поддержку со стороны окружающих его людей.

5-6 - ситуация начинает приобретать критический характер. Пациент всё больше погружается в пессимизм и бессилие перед создавшейся ситуацией, активно продумывает место, время и способ ухода из жизни. Скептически относится и не верит в помощь со стороны. В данной ситуации уже есть необходимость обратиться к психиатру и желательно добровольно госпитализировать пациента, а также начать ему фармакологическое лечение.

7-8 - ситуация рассматривается как критическая, уже была попытка суицида в течение последней недели, прерванная кем-то или чем-то. Существует уже реальный выбранный способ свести счёты с жизнью, в клинической картине доминируют депрессивные или психотические симптомы, 
отрешенность, отчаяние. Возможно, речь идёт уже о необходимости насильственной госпитализации закрытое психиатрическое отделение, как превенции повторной суицидальной попытки.

9 - была совершена попытка суицида в последние 72 часа (диффреренцировать от попытки по типу "суицидальный шантаж"). Как правило, такое состояние связано с такими заболеваниями: психоз с императивными слуховыми и\или зрительными угрожающими галлюцинациями, тяжелая депрессия, внезапная, невосполнимая потеря индивидуально- значимого "другого", тяжёлые повторяющиеся приступы тревоги или паники. По мнению авторов, другие причины также возможны, но гораздо менее часты. Психическое состояние пациента требует немедленной адекватной терапии и изоляции пациента, в виде добровольной или принудительной госпитализации в закрытое отделение, с последующим фрармакологическим и психотерапевтическим лечением.

10 - сомнительная или чрезмерная демонстративная суицидальность, связанная как правило с импульсивным поведением, в рамках нарушения личности кластера "B" (американская классификация DSM-5 рассматривает в этом кластере "В" - пограничное, антисоциальное, нарциссическое и истероидное расстройства личности или же у личности есть корыстные мотивы, именуемые "суицидальным шантажом", то есть "мнимая угроза собственной жизни", с целью получения любых выгод и привилегий (получение денежного вознаграждения, изменение условий работы, возобновление супружеских отношений после разрыва и т.д.) После того, как пациент самостоятельно оценит риск собственной суицидальности, психотерапевт или психолог должен сам, профессионально-объективно оценить текущее состояние суицидальной активности пациента, полученной из предварительной беседы. Затем выбрать оптимальную тактику для прогноза и превенции суицидального поведения. Кроме того, сама "суицидальная линейка" обладает определенным психотерапевтическим действием на пациента: во-первых он впервые пробует самостоятельно контролировать "фатальную ситуацию" и она уже не выглядит для него такой катастрофической, во-вторых - динамическое уменьшение в баллах вовлеченности в суицидальные мысли, вселяет большую уверенность пациента в собственные силы и надежду на выздоровление, и в-третьих - в дальнейшем, например при выписке, пациент может самостоятельно отслеживать свои суицидальные тенденции и вовремя обратиться за помощью к специалисту.

Профрилактика самоубийства астеников (ЦВЕТКОВ) направлена, прежде всего на повышение требовательности к самому себе и формировании самодисциплины. (настойчивость VS эгоцентризм). Профилактика самоубийства у нормостеников (САДОВНИКОВ) базируется на основании 
других факторов (осмотрительность и личностная независимость VS косности мышления). Профилактика самоубийств у гиперстеников (ГОРШКОВ) должна быть построена по принципу (уравновешенность и конструктивность VS жертвенности). Астеник переключается на "конструктивное бегство" в творчество, спорт или хобби. Гиперстеник путём личностного мониторинга во времени отслеживает и контролирует развитие стрессовой ситуации и оценивает фатальность последствий. Нормостеник изыскивает дополнительные собственные внутренние психофизические резервы для продолжения борьбы с создавшейся неблагоприятной ситуацией. Замена на новый, более адаптивный тип реагирования, используется как "иллюзия свободного и осознанного выбора", таким образом, каждому психотипу предлагают на выбор две дополнительные новые реакции реагирования на фррустрирующую ситуацию, которые ранее были характерны двум другим психотипам. К примеру, астенику (цветку) умение вырабатывать активную настойчивость в преодолении стрессовой ситуации как у нормостеника (садовника) или умение принимать неблагоприятную ситуацию, взвешивать и выжидать как у гиперстеника (горшка) и т.д. При этом, пациент сам или первоначально с помощью психотерапевта, выбирает новый оптимальный для него, способ реагирования, проигрывая различные фрустрирующие ситуации на несколько "ходов" вперед.

\section{Литература}

1. Амбрумова А. Г., Калашникова О. Э. Клинико-психологические аспекты самоубийства. Социальная и клиническая психиатрия, 1998, $4(8)$, с. $65-77$

2. Конечный Р., Боухал М. Психология в медицине. Авиценум. Прага. 1983. 405 стр.

3. Любов Е.Б., Цупрун В.Е. Суицидальное поведение и шизофрения: биопсихосоциальный подход в диагностике, лечении и профилактике // Суицидология. 2013. Т. 4. № 3 (12). с. 3-16.

4. Рязанцев С. Философия смерти. СПб., 1994. 319 стр.

5. Рахимкулова А.С., Розанов В.А. Суицидальность и склонность к риску у подростков: биопсихосоциальный синтез // Суицидология. 2013. Т. 4. № 2 (11). с. 7-25.

6. Холмогорова А.Б. Биопсихосоциальная модель как методологическая основа изучения психических расстройств // Социальная и клиническая психиатрия. 2002. Т. 12. № 3. с. 97-104.

7. Engel G.L. The clinical application of the biopsychosocial model. Am J Psychiatry 1980, 137:5, May, pp. $535-544$. 


\section{PREVENTION OF SUICIDE, NEW HORIZONTS}

Borokhov A. (Hebrew University of Jerusalem, Jerusalem, Israel) Borokhov B. (Rehabilitation and corrective program «SELA», Jerusalem, Israel) adsamuray@gmail.com,borisdo69@gmail.com

The article presents a conceptual model for assessing suicidal activity and risk, developed by the authors. This model is compiled taking into account the expanded and supplemented bio-psycho-social model of Georg Engel (Engel G., 1977), which consists of three types of constructs: biological, psychological and social. Actually, the constitutional psychotype of a person is the genetic predisposition of each specific person belonging to one of three somatotypes (normostenic, asthenic, hypersthenic) and the expected basic individual behavioral response (Fight -Flight -Freeze), which is almost always manifested in response to a stressful situation. In clinical psychology, it is generally accepted that almost any individual who is truly engulfed in suicidal thoughts, neither only does not have, but does not seek an alternative solution. Figuratively speaking, he develops "tunnel vision", that is, he sees a very minimal range of solutions to his problem, more precisely one - fatal. Therefore, we came to the conclusion that it is necessary to create a system of "external and internal anchors" that keep the patient from committing a suicidal act. Therefore, we came to the conclusion that it is necessary to create a system of "external and internal anchors" that keep the patient from committing a suicidal act. It was based on several basic questions-constructs, the answers to which could be obtained in the process of a doctor / psychologist-patient dialogue. Thus, an individual scheme of psychotherapeutic treatment was built, the purpose of which is to keep a person from a suicidal attempt. So, four basic questions: "What?", "Who?", "What?" and "How?". The article also presents a specially developed author's scale (A.B) *, which is called the "suicidal ruler", BARS-2000 (Rapid Active Calculation of Suicidality), which was successfully used not only in the admission rooms of psychiatric hospitals for the civilian population, but also for checking persons, noncommissioned officers of the conscript service of the Israel Defense Forces.

Keywords: suicide, psychofactors, psychotype, scale of self-diagnosis, prevention. 